\title{
Thousand Organisms per Milliliter
}

National Cancer Institute

\section{Source}

National Cancer Institute. Thousand Organisms per Milliliter. NCI Thesaurus. Code C71195.

A unit of measure of organism concentration expressed in thousands of organisms per unit of volume equal to one milliliter. 